Revista aSEPHallus de Orientação Lacaniana

Núcleo Sephora de Pesquisa sobre o Moderno e o Contemporâneo

ISSN 1809 - $709 \mathrm{X}$

\title{
Psicopatologia e soluções identitárias: efeito das reconfigurações do imaginário na contemporaneidade
}

Douglas Nunes Abreu

Psicanalista; Pós-Doutor em Psicologia UFJF

Doutor em Teoria Psicanalítica UFRJ

Professor Suprema / UNIPAC / UNIFENAS

Membro do ISEPOL

Resumo: O presente trabalho discute as repercussões no âmbito da psicopatologia das reconfigurações do imaginário na contemporaneidade, especificamente no que tange às soluções identitárias. Apontamos os marcadores históricos na psicopatologia que contribuíram para a emergência essa nova modalidade de laço social, exemplificando a temática, a partir dos exemplos do autismo e da bipolaridade.

Palavras-chave: psicopatologia; DSM; soluções identitárias; autismo; bipolaridade.

\section{Psychopathologie et solutions identitaires: effet des reconfigurations de l'imaginaire à l'époque} contemporaine

Cet article discute des répercussions dans le cadre de la psychopathologie des reconfigurations de l'imaginaire à l'époque contemporaine, en particulier en ce qui concerne les solutions identitaires. Nous rappelons les marqueurs historiques de la psychopathologie qui ont contribué à l'émergence de cette nouvelle modalité de lien social, exemplifiant la thématique, à partir des exemples de l'autisme et de la bipolarité.

Mots-clés: psychopathologie; DSM; solutions identitaires; autisme; bipolarité.

Psychopathology and identity solutions: effect of reconfigurations of the imaginary in contemporary times

The present work discusses the repercussions within the psychopathology scope of the reconfigurations of the imaginary in contemporaneity, specifically regarding identity solutions. We point out the historical markers in psychopathology that contributed to the emergence of this new form of social link, exemplifying the theme from the examples of autism and bipolarity.

Keywords: psychopathology; DSM; identity solutions; autism; bipolarity. 


\title{
Psicopatologia e soluções identitárias: efeito das reconfigurações do imaginário na contemporaneidade ${ }^{1}$
}

\author{
Douglas Nunes Abreu
}

A crítica efetuada por Maleval (2003) ao campo da psicopatologia hoje serve de ponto de partida para este ensaio. Com a publicação da terceira versão do Manual de Transtornos Mentais da Associação de Psiquiatria Norte-Americana, em 1980, testemunhamos um rompimento com as categorias clássicas da psiquiatria, uma ampliação dos espectros diagnósticos e uma consequente elevação das taxas de incidência de algumas patologias, tais como o autismo e a bipolaridade. Serpa Jr. (2007) corrobora com essa visão, tecendo uma posição crítica sobre o campo hoje que, segundo ele, é marcado por uma perspectiva rasa e sem espessura conceitual, se constituindo como um instrumento meramente descritivo e operacional.

Ao promover essa ruptura, Russo e Venâncio (2006) destacam três níveis desse acontecimento: ao nível da estrutura conceitual, rompendo com a multiplicidade de posições acerca das classificações e ordenamentos psíquicos; ao nível da hegemonia dos campos de saberes concorrentes, efetuando uma desvinculação radical em relação ao saber psicanalítico; e por fim, ao nível das representações sociais relativas ao indivíduo contemporâneo, que subverte as relações entre o normal e o patológico, promovendo o engendramento de grupos identitários organizados a partir de certas patologias.

Nos ocuparemos, neste ensaio, desta nova modalidade de laço social, típica de nossa sociedade contemporânea, onde emergem, de forma exponencial, as tribos de iguais, associações organizadas pela vinculação de seus membros não mais pelos ideais societários que conduziam os arranjos coletivos de outrora, mas sim, pela vertente objetal. Ou seja, o diagnóstico psicopatológico, ao invés de servir de orientação para a clínica, funciona como marca identificatória, fazendo surgir cada vez mais grupos de obesos, de anoréticos, de bipolares, de autistas, dentre outros. Entendemos que as transformações no campo da psicologia comportam expressões de uma época, vejamos.

Desde que Jean F. Lyotard publicou A Condição Pós-Moderna, em 1979, ganhou força o que já se anunciava na esteia dos movimentos de maio de 68, uma nova era ligada ao crescimento econômico de uma sociedade pós-industrial, na qual o conhecimento (saber) tornara-se a principal força econômica de produção. Esse pacto afetou o campo da ciência produzindo novas discursividades, que promovem efeitos na subjetividade e na composição do laço social hoje.

Coelho dos Santos (2015) advoga a favor do termo hipermodernidade para designar esse momento contemporâneo onde testemunhamos duas características fundamentais: o desmentido da função do Nome-do-Pai como agente da lei simbólica, e a ascensão do objeto $a$ ao zênite da civilização (Lacan, 1973). Se a primeira característica pode ser observada na queda das grandes utopias comunitárias (Lacan, 1969) e na falência das figuras de autoridade simbólica como agentes de regulação, a segunda característica se explicita no rebaixamento dos objetos que tinham outrora 
a dignidade de Coisa (Ding) à objetos trocáveis, reduzidos ao seu valor de uso, de mercado (Dufour, 2008).

Nesse contexto, a pesquisa desenvolvida pelo GT da ANPEPP (2016-2017), sob o título Reconfigurações do Imaginário na Contemporaneidade, se ocupou dos impasses testemunhados na clínica contemporânea onde o narcisismo (eu ideal) opera sem a função simbólica do Nome-do-Pai (ideal do eu). Diante do império dos objetos, das imagens e da lei do mercado de consumo em que mergulhou a civilização atual, os pesquisadores elencaram temáticas que interrogavam os efeitos desta configuração no laço social e seus impactos na direção do tratamento.

A partir da perspectiva inaugurada por Michel Foucault, verificou-se o deslocamento da organização social orientada pelo pacto simbólico para a multiplicidade das normas sociais decorrentes dos acordos entre os pares ou grupos, nível do contrato intersubjetivo. Com isso, constatou-se que, ao transpor a responsabilidade subjetiva para a responsabilidade contratual (ou responsabilidade do Estado), as patologias tradicionais, estruturalmente constituídas (categorias clínicas, cujo horizonte emerge na relação com a função simbólica do Nome-do-Pai), podem dar lugar às patologias do imaginário, patologias narcísicas e suas soluções identitárias (Coelho dos Santos, 2014).

As perturbações psíquicas contemporâneas que testemunhamos nas cidades e na clínica, trazem a expressão da apresentação dos sintomas no laço social específico desta época. De acordo com Brousse (2009), testemunhamos na clínica o surgimento de uma série de manifestações sintomáticas que se caracterizam pela desregulação dos corpos nos valores e hábitos que organizam a realidade (alimentares, sexuais, de sono, de horários, de organização da rotina diária). A marca distintiva dos novos sintomas é o fato de que o modo de usufruir do corpo revela o excesso pulsional disjunto do discurso coletivo. Desde as toxicomanias até os distúrbios alimentares, passando pelas mais variadas compulsões, os novos sintomas não constituem formações do inconsciente estruturadas simbolicamente, e, por isso, não se prestam diretamente à interpretação, não portam um desejo cifrado como enigma. São soluções para as exigências pulsionais que prescindem do mecanismo do recalque. Capazes de produzir uma satisfação direta com o objeto, sem extrair dela a pequena cota de gozo insatisfeito que seria devida às exigências da castração. São a prova de que o significante do Nome-do-Pai não é mais sintoma coletivo. Os novos sintomas denunciam que os ideais coletivos que dependem deste significante, e que outrora organizavam o laço social, foram rebaixados graças à radicalização das ideologias individualistas que absolutizam o direito ao gozo autoerótico.

O discurso do inconsciente que regulava o fluxo pulsional articulado à cadeia significante foi substituído por um novo discurso que incidiu diretamente na regulação dos gozos. Lacan (19721973) o nomeou como discurso capitalista, que subverte o discurso do mestre, destituindo o agente simbólico e colocando em seu lugar o sujeito do consumo. Os objetos, entendidos nesta variação discursiva como gadgets (objetos de consumo), são responsáveis por engendrar a produção e o 
consumo: drogas, sexo, bebidas, comidas, remédios, suplementos, dívidas, engenhocas eletrônicas, dentre tantos outros objetos de mercado. Atrelado ao progresso da ciência, e principalmente aos usos dos discursos que decorrem da ciência, o discurso capitalista produziu consequências sobre as práticas psiquiátricas, psicológicas e psicanalíticas, incidindo assim no campo da psicopatologia.

Seriam apenas as novas apresentações sintomáticas que incidiram no campo da psicopatologia forçando sua modificação, ou podemos encontrar no seio deste ramo da ciência multifacetada transformações metodológicas que também produziram e fomentaram novas formas de subjetivação, de compreensão e de solução para o sofrimento psíquico? Ao nos debruçarmos sobre a história da psicopatologia (Abreu \& Simanke, 2014), foi possível destacar alguns marcadores que constituíram modificações substanciais no campo dos diagnósticos mentais nas últimas décadas. O lançamento, em 2013, pela Associação de Psiquiatria Americana - APA, da quinta versão do DSM - Manual Diagnóstico e Estatístico dos Transtornos Mentais, reconfigurou a noção categorial das grandes síndromes psiquiátricas tradicionais em prol da ampliação da noção dimensional, operada pelos espectros, para organizar sua lógica nosológica.

O campo da psicopatologia nasce de uma longa tradição epistêmica, oriunda da interseção entre as ciências humanas - como a filosofia e a psicologia, entre outros - e as ciências biológicas, que sustentam a medicina. As concepções sobre a ontogênese dos quadros psicopatológicos oscilaram na história desta ciência entre dois polos distintos: a organogênese, método anatomopatológico e biológico, e a psicogênese, método clínico e psicodinâmico (Maleval, 2008), respectivamente: uma que congrega os defensores do método nomotético - o da física e da biologia, o método experimental que visa o universal, e outra dos partidários do método ideográfico, o da história de vida, que apreende o singular no âmbito do laço social. O conhecimento em psicopatologia pode instaurar-se através dessas duas vias distintas, que se enlaçam constituindo um importante e denso campo de investigação científica.

Entretanto, diversos autores apontam uma transição ocorrida na psiquiatria nos últimos anos, que desembocaram na psiquiatria contemporânea - operacional e ateórica (Serpa Jr et al, 2007; França Neto, 2012). Essa perspectiva rompeu com a tradição dos clássicos, como Kraepelin (1856-1926) e Jaspers (1883-1969), passando a se orientar pela estatística e pelo enfoque biológico. O saber psicopatológico entrou no mercado, tendo no avanço da indústria farmacêutica seu motor mais significativo, e passou a ser constituído como um manual descritivo-operacional dos transtornos mentais, que renuncia ao conhecimento epistêmico de sua origem e engendra o processo de patologização da sociedade e do consumo generalizado de medicamentos. A revisão realizada em 1974, por ocasião do DSM-III (publicado em 1980), que rompeu com o paradigma psicodinâmico, reduziu o interesse pela ontologia e pela etiologia da afecção, privilegiando, assim, o caráter descritivo e semiológico do transtorno mental. As próximas versões radicalizam as posições organicistas, evidenciando o privilégio pela descrição das sintomatologias em detrimento da etiologia, abrindo portas para a passagem da lógica categorial à lógica dimensional que virá em sua 
última versão (Dunker \& Kyrillos Neto, 2011). O DSM-V, lançado em 2013, apresenta as patologias psíquicas a partir de dimensões, considerando a intensidade das afecções e, a partir desta intensidade, estabelece uma espécie de continuum, ou espectros, na ordenação dos transtornos mentais. Acompanhemos como estes fatos se apresentaram em relação ao tema do autismo e da bipolaridade.

Tendlarz (2017) relembra que o conceito de autismo foi introduzido em 1943 por Leo Kanner, sob a rubrica de autismo infantil precoce. Na mesma época, o austríaco Hans Asperger apresentou um quadro de autismo menos severo e mais preservado em suas relações sociais: a síndrome de Asperger. No início das discussões sobre o tema, entre as décadas de 1940 e 1960, predominaram as explicações do autismo marcadas pela associação da psicanálise com a clínica psiquiátrica. Porém, a partir dos anos 60, testemunhamos um deslocamento para explicações orgânicas, especialmente cerebrais, do transtorno. Esse deslocamento das teses psicodinâmicas e a aproximação com as neurociências, configura o transtorno autista como uma doença de etiologia orgânica (principalmente cerebral e/ou genética).

A quinta versão do DSM elimina essa distinção ao introduzir a noção de espectro autista e suas gradações - leve, moderado e severo -, tornando-se, hoje, um diagnóstico muito mais ampliado, que inclui uma tipologia variada. Aflalo (2014) também demonstra o alargamento dos critérios diagnósticos ao longo das transformações ocorridas no DSM e sua relação com a expansão da incidência de autismo, que chega a evocar o termo epidemia. Laurent (2011) lembra que desde o DSM-4, com a noção de Transtorno Global do Desenvolvimento (TGD), crianças com dificuldades na reciprocidade social, na comunicação, e que apresentam restrições em suas condutas, passam a poder ser incluídas no espectro autista.

Segundo Ansermet e Giacobino (2013), a elaboração da concepção de Transtorno d do Espectro Autista (TSA), a partir do DSM-5, ampliou de forma ainda mais significante sua epidemiologia. Segundo os estudos de Mitka (2010), a prevalência do autismo cresceu $57 \%$ entre 2002 e 2006, e, segundo os estudos de Hertz-Piccriotto et al (2009), teria crescido 600\% entre 1990 e 2006. Entretanto, Ansermet apresenta os estudos de Fisch (2012), indicando que se partimos de critérios fixos e constantes de avaliação diagnóstica encontraremos uma estabilidade na prevalência nas últimas décadas, o que não ocorre se modificarmos os métodos de avaliação de acordo com a evolução do conceito ao longo das versões do DSM. O que se verifica nos estudos de Ansermet e Giacobino (2013) é que, apesar dos avanços e méritos, os estudos atuais sobre o autismo esbarram na impossibilidade de encontrar uma relação causal simples entre bases genéricas e fenômenos clínicos, o que aponta para as múltiplas e heterogêneas causalidades.

No que tange à psicopatologia psicanalítica, também encontramos modificações substanciais na apreensão do autismo. Segundo Tendlarz (2017), Bleuler o situa como uma modalidade da esquizofrenia, posição que se manteve presente nos pós-freudianos mesmo depois dos estudos de Kanner. Baseados nas descrições de Kanner sobre as relações frias entre mães e filhos autistas nos 
primeiros momentos de vida, e, assentados na teoria lacaniana do Estádio do Espelho, vários psicanalistas (Jerusalinsky, 1993; Laznik-Penot, 1997) sustentaram a tese da falta de um olhar primordial sobre a criança, marca do desejo, nestas relações maternais. Esta concepção engendrou resistências radicais dos familiares de autistas em relação à psicanálise.

Coube ao casal Rosine e Robert Lefort (1980) retirar o autismo do campo das psicoses e sugerir uma estrutura a parte para essa afecção. Apoiados nestes estudos e nas colocações de Jacques Lacan na conferência sobre o sintoma proferia em Genebra (1975), Jacques-Alain Miller, Eric Laurent e Jean-Claude Maleval, avançaram nesta perspectiva, elencando característica específicas e constates que sustentam a tese de uma quarta estrutura, em especial um rechaço da alienação significante e de um retorno do gozo sobre uma borda. Essa posição autística retém o gozo vocal e impede a conexão do gozo com a palavra, instituindo uma carapaça na sua dinâmica libidinal. A borda autista, segundo Maleval (2011), funciona como uma proteção frente a um Outro ameaçador, dispondo de três componentes essenciais: a imagem do duplo, as ilhotas de competência e o objeto autista.

Ortega (2008) apresenta um interessante estudo acerca do autismo hoje, situando-o entre dois polos opostos. De um lado, o desenvolvimento histórico da psicopatologia centrado nas pesquisas genéticas e de neuroimagem constituem bases para uma apreensão do autismo como distúrbio de causa orgânica, concebendo o autista como um sujeito puramente cerebral. De outro lado, vemos avançar o movimento da neurodiversidade (Singer, 1999), que entende o autismo como sendo apenas uma nova categoria de diferença neuronal, ou seja, uma nova configuração biopsíquica-neuronal, atípica, porém tão normal quanto todas as outras formas que dela diferem. Os adeptos do movimento da neurodiversidade são, em sua maioria, familiares e autistas, principalmente os de alto desempenho, que ao aderirem a esta perspectiva promovem uma negação do diagnóstico e a composição de grupos de pares. Várias associações afirmam a identidade autista e celebram essa subcultura.

Esse movimento aponta para soluções identitárias, compreendendo o autismo não como uma doença que se tem, mas como algo que se é. Segundo Ortega (2008), a biossociabilidade representa um contexto geral onde essa questão se insere. A biossociabilidade corresponde a uma

[...] forma de sociabilidade apolítica constituída por grupos de interesses privados, não mais reunidos segundo critérios de agrupamento tradicional, como raça, classe, estamento, orientação política, como acontecia na biopolítica clássica oitocentista analisada por Foucault (1976, 1997, 1999), mas sim segundo critérios de saúde, performances corporais, doenças específicas, longevidade, entre outros. (Ortega, 2008, p. 488-489) 
Nesta perspectiva, as concepções psicológicas e a responsabilidade interna de cada pessoa "são deslocadas para a exterioridade, dando lugar à constituição de identidades somáticas, as bioidentidades" (Ortega, 2008).

O mesmo processo pode ser observado em relação à antiga nosografia da Psicose Maníaco Depressiva (PMD), formalizada por Emil Kraepelin (1899) a partir dos estudos anteriores de J. P. Falret e Baillarger (1854). Nesta perspectiva, os sintomas eram descritos, classificados e ordenados de maneira a configurarem uma entidade nosológica clara, um tipo clínico de psicose. Alkmim (2015), partindo dos movimentos de revisão dos critérios diagnósticos nas últimas décadas, culminando no abandono de "grande parte das construções teórico-clínicas da psiquiatria clássica em prol de um pragmatismo ateórico" (Alkimim, 2015, p. 2), discute a passagem da Psicose Maníaco Depressiva para o Transtorno do Humor Bipolar. Como já apontado por Maleval (2003), a terceira versão do DSM, em 1980, foi o marco dessa mudança radical no campo da psicopatologia psiquiátrica. Nesta versão, a discussão sobre a etiologia das afecções foi abandonada e sua centralidade passou a ser baseada em uma perspectiva baseada na observação objetiva de sinais e sintomas, desmontando as entidades nosológicas tradicionais. A PMD foi desmantelada e dissolvida em diversas possibilidades diagnósticas, especialmente no grupo dos transtornos afetivos. A edição seguinte, DSM-4, apresentou uma nova divisão dos transtornos bipolares, com a transposição do termo Transtorno Afetivo para o termo Transtorno de Humor, com incidência maior dos aspectos biológicos e neuronais. Em 2013, com a publicação do DSM-5, amplia-se a vinculação com pesquisas e progressos da neurociência, da neuroimagem, da epidemiologia e da genética, com o alargamento de sua apreensão diagnóstica. Alterações de temperamento passam a poderem ser incluídas no espectro dos transtornos de humor, totalmente desarticuladas das alterações típicas da PMD, tais como as alterações do pensamento e do juízo. Esse foi um fator decisivo no que tange às modificações estatísticas, como demonstra Leader (2015), pois a epidemiologia dos transtornos do humor foi drasticamente ampliada, sofrendo um vertiginoso aumento de $4.000 \%$ a partir dos anos de 1990.

Segundo Bogochvol (2014), a bipolaridade hoje tornou-se uma palavra de uso comum, corriqueiro, sem comportar mais o constrangimento e delicadeza de sua vinculação com o campo das psicoses. O mesmo fenômeno observado no autismo pode ser visto também em relação à bipolaridade. Proliferam sites de associações e comunidades de pacientes que se identificam à esta patologia e fazem de sua doença o objeto necessário para promover o laço tribalista típico da hipermodernidade.

Segundo Ortega (2008), a relativização no campo da psicopatologia engendra soluções identitárias operadas pela via do imaginário. Tal como testemunhamos nos grupos identitários, que organizam o universo das tatuagens, dos piercings e dos implantes subcutâneos, dentre outros, 0 que verificamos são tentativas de localização específica da imagem corporal à identidade subjetiva. No lugar da constituição psíquica engendrada pelos vínculos simbólicos, a localização do ser hoje 
pode ser balizada pela dimensão corporal especular. Uma espécie de suplência de identidade, que difere daquelas que Ihe são atribuídas pela dimensão do Outro, da cultura e do romance familiar. Essa tentação atual em franca expansão, a política identitária, corre o risco de homogeneizar as diferenças, suprimindo a singularidade. Nesta perspectiva, nos apontam Aflalo (2014) e Laurent (2014), vemos emergir uma mercadorização dos corpos através das imagens. Novos identidades, novos mercados, uma lógica que apaga a experiência individual, transformando a dimensão subjetiva em modalidades capitalistas de vínculo social puramente imagéticas.

\section{Nota:}

${ }^{1}$ Produção vinculada à pesquisa de pós-doutoramento realizada no Programa de Pós-graduação em Psicologia, vinculado à UFJF - Universidade Federal de Juiz de Fora, sob orientação do Professor Dr. Richard Theisen Simanke, em parceria com o ISEPOL - Instituto Sephora de Ensino e Pesquisa de Orientação Lacaniana, vinculado à UFRJ - Universidade Federal do Rio de Janeiro, sob coorientação da Dra. Tânia Coelho dos Santos.

\section{Referências Bibliográficas}

Abreu, D. N. \& Simanke, R. T. (2014). A psicanálise e o campo da psicopatologia: a abordagem lacaniana. Psicanálise em Perspectiva V: novos estudos em história e epistemologia da psicanálise, (Vol. 1, pp. 133-144). Curitiba: Editora CRV e CAPES.

Aflalo, A. (2014). Autismo: novos espectros, novos mercados. Petrópolis: KBR.

Alkimim, W. (2015). O que é o transtorno bipolar? Almanaque. Recuperado de http://almanaquepsicanalise.com.br/wp-content/uploads/2015/09/3.-O-que-\%C3\%A9-oTranstorno-Bipolar-Wellerson-D.-Alkimim.pdf.

Ansermet, F. \& Giacobino, A. (2013). Autismo: a cada um seu genoma. Petrópolis: KBR.

Brousse, M.-H. (2009). La psychose ordinaire à la lumière de la théorie lacanienne du discours. Quarto - Revue de psychanalyse, 94/95, 10-15. Bruxelas: ECF.

Coelho dos Santos, T. (2015). O olhar sem véu: transparência e obscenidade. Revista aSEPHallus de Orientação Lacaniana, 10(20). Recuperado de http:// www.isepol.com/asephallus.

Coelho dos Santos, T.; Santiago, J. \& Martello, A. (Orgs). (2014). Os Corpos Falantes e a Normatividade do Supersocial. Rio de Janeiro: Cia de Freud.

Dufour, D.-R. (2008). O Divino Mercado: a revolução cultural liberal. Rio de Janeiro: Companhia de Freud.

Dunker, C. I. L. \& Kyrillos Neto, F. (2011, dez.). A crítica psicanalítica do DSM-IV: breve história do casamento psicopatológico entre psicanálise e psiquiatria. Revista latino-americana de psicopatologia fundamental, 14(4). São Paulo.

Fisch, G. S. (2012). Nosology and Epidemiology in Autism. Classification Counts. American Journal of Medical Genetics Part C: Seminars in Medical Genetics, 160c(2). 
França Neto, O. (2012). O saber e a verdade no DSM. Psicopatologia em debate: controvérsias sobre o DSM, 155-170. Barbacena: EdUEMG.

Hertz-Picciotto, I. \& Delwiche, L. (2009). The Rise in Autism and the Role of Age at Diagnosis, 20(1). Jerusalinsky, A. (1993). Psicose e autismo na infância: uma questão de linguagem. Revista da APPOA, (9), 62-73.

Lacan, J. (2003). Nota sobre a criança. Outros escritos, 369-370. Rio de Janeiro: Zahar (Trabalho originalmente publicado em 1969).

Lacan, J. (2003). O aturdito. Outros Escritos, 448-497. Rio de Janeiro: Zahar (Trabalho originalmente publicado em 1972).

Lacan, J. (2003). Televisão. Outros Escritos, 508-543. Rio de Janeiro: Zahar (Trabalho originalmente publicado em 1973).

Lacan, J. (1998, dez.). Conferência em Genebra sobre o Sintoma. Opção Lacaniana, 23, 6-16. São Paulo: Eólia. (Trabalho originalmente publicado em 1975).

Laurent, É. (2011). Spectres de l'autisme. Revue de La Cause Freudienne, 78, 53-63. Paris: ECF.

Laurent, É. (2014). A batalha do autismo: da clínica à política. Rio de Janeiro: Zahar.

Laznik-Penot, M.-C. (1997). Rumo à palavra: três crianças autistas em psicanálise. São Paulo.

Leader, D. (2015). Simplemente bipolar. Rio de Janeiro: Zahar.

Lefort, R. \& Robert (1980). Naissance de l'Autre: Deux psychanalyses, Nadia, 13 mois, MarieFrançoise, 30 mois. Paris: Seuil.

Lyotard, J.-F. (1998). A condição pós-moderna. Rio de Janeiro: José Olympio (Trabalho originalmente publicado em 1979).

Maleval, J.-C. (2011). Langue verbeuse, langue factuelle et phrases spontanées chez l'autisme. Revue de La Cause Freudienne, 78, 77-92. Paris: ECF.

Maleval, J.-C. (2008). A unidade da psicologia sobreviveu. aSEPHallus - Revista eletrônica do Núcleo Sephora de pesquisa sobre o moderno e o contemporâneo, 5(9). Rio de Janeiro: ISEPOL.

Miller, J.-A. (2011). Perspectivas dos Escritos e Outros escritos de Lacan: entre desejo e gozo. Rio de Janeiro: Zahar (Trabalho originalmente publicado em 2008-2009).

Mitra, M. (2010). Rising Autism Rates Still Pose a Mystery. JAMA, 303(7).

Ortega, F. (2008). O sujeito cerebral e o movimento da neurodiversidade. Mana, 14(2).

Russo, J. \& Venâncio, A. T. (2006). Classificando as pessoas e suas perturbações: a "revolução terminológica" do DSM III. Revista Latinoamericana de Psicopatologia Fundamental, 9(3), 460483.

Serpa Jr, O. D. et al. (2007). A inclusão da subjetividade no ensino da psicopatologia. Interface. Comunicação, Saúde e Educação, 11, 207-222.

Serpa Jr, O. D. (2007). Subjetividade, valor e corporeidade: os desafios da psicopatologia. Psicopatologia Hoje, 25-101.Rio de Janeiro: CCS/UFRJ.

Revista aSEPHallus de Orientação Lacaniana. Rio de Janeiro, 12(24), 113-122, mai. a out. 2017. 
Singer, J. (1999). Why can't you be normal for once in your life?' From a 'problem with no name' to the emergence of a new category of difference. Disability discourse, 59-67. Philadelphia: Open University Press.

Tendlarz, S. (2017, ago.). Lacan e o autismo em nossa época. Opção Lacaniana online. Nova série, 8(23). Recuperado de http://www.opcaolacaniana.com.br/texto5.html.

Citacão/Citation: Abreu, D. N. (mai. a out. 2017). Psicopatologia e soluções identitárias: efeito das reconfigurações do imaginário na contemporaneidade. Revista aSEPHallus de Orientação Lacaniana, 12(24), 113-122. Disponível em www.isepol.com/asephallus. doi: 10.17852/1809-709x.2019v12n24p113-122.

Editor do artigo: Tania Coelho dos Santos.

Recebido/Received: 02/10/2017 / 10/02/2017.

Aceito/Accepted: 18/10/2017 / 10/18/2017.

Copyright: (C) 2013 Associação Núcleo Sephora de Pesquisa sobre o moderno e o contemporâneo. Este é um artigo de livre acesso, que permite uso irrestrito, distribuição e reprodução em qualquer meio, desde que o autor e a fonte sejam citados/This is an open-access article, which permites unrestricted use, distribution, and reproduction in any medium, provided the author and source are credited. 